\title{
The Influence of Personal Values on the Transition towards Health-conscious Diet: a Segmentation Approach
}

\author{
Zoltán Szakály ${ }^{1}$ Péter Balogh², Helga Jasák ${ }^{1}$, Sára Szabó ${ }^{3, *}$, Viktória Szente ${ }^{3}$ \\ ${ }^{1}$ Institute of Marketing and Commerce, Faculty of Applied Economics and Rural Development, University of Debrecen, Debrecen, \\ Hungary \\ ${ }^{2}$ Department of Economic Analytical Methodology and Statistics, Faculty of Applied Economics and Rural Development, University \\ of Debrecen, Debrecen, Hungary \\ ${ }^{3}$ Department of Marketing and Trade, Faculty of Economic Science, Kaposvár University, Kaposvár, Hungary \\ *Corresponding author: szabo.sara@ke.hu
}

Received July 10, 2014; Revised July 31, 2014; Accepted August 13, 2014

\begin{abstract}
The main objective of this survey is to reveal relationship between personal values and change in healthconscious diet and food purchase behavior on the basis of Kahle's List of Values (LOV). In order to achieve this objective, a nationwide representative questionnaire-based survey was launched with 1000 participants in Hungary. According to the results, for the Hungarian population the most important social value is security, which is followed by a desire for a happy and enjoyable life. In Hungary, a new factor structure of the personal values had been identified and consumer segmentation was made based on the new factors. According to the segmentation the authors defined Moderately Value Driven, Security Seeker, Disappointed, and Value Oriented consumers. The group of the Value Oriented consumers is the primary target group for health protective food products, because from among the four segments the Value Oriented group switched to a more health-conscious diet at the biggest rate (18.5\%) and they are also the most devoted to health-conscious food purchase. Closest to them are the Security Seekers, whose need for security also manifests itself in conscious food consumption. This shows that the rate of value orientation is defining for activity. As a result, in this field, great opportunities lie both in entrepreneurial and collective marketing communications. The results of the research can be used by those (functional) food producers who determine their target groups and make their marketing programs based on social values.
\end{abstract}

Keywords: personal values, segmentation, health behavior, food purchase

Cite This Article: Zoltán Szakály, Péter Balogh, Helga Jasák, Sára Szabó, and Viktória Szente, "The Influence of Personal Values on the Transition towards Health-conscious Diet: a Segmentation Approach.” Journal of Food and Nutrition Research, vol. 2, no. 8 (2014): 476-484. doi: 10.12691/jfnr-2-8-8.

\section{Introduction}

Over the past decades, a number of research studies have focused on a market segmentation based on human values. A common assumption of these investigations was that values are closely related to behavior, often more closely than personality traits. At the same time, values are less numerous and more centralized, and are connected to motivation more directly than attitudes [1,2].

The literature reveals the following measurement tools: the Rokeach value system (RVS) [3]; the values and lifestyles system (VALS) [4]; the list of values (LOV) [5] and Schwartz's human values [6]. Due to its simplicity and widespread utility in marketing research, Kahle's List of Values [5] is the most widespread. It is considered well-organized and it has assessable sets of variables that are less various, more centrally held and more closely associated to stimulus than demographic and psychographics measures. The LOV has also proven its effectiveness in cross-cultural applications [7,8]. A number of studies $[2,5,9,10]$ indicate that the LOV is suitable for understanding and/or predicting (consumer) behavior.

The List of Values (LOV) was developed by researchers at the University of Michigan Survey Research Centre [5]. According to Beatty et al. [11], the instrument called the LOV was developed from a theoretical basis proposed by Feather [12], Maslow's [13] hierarchy of needs, Rokeach's [3] terminal values and other theories in value research. An LOV instrument consists of the following nine items: sense of security; sense of belonging; being well respected; fun and enjoyment in life; warm relationships with others; selfrespect; self-fulfillment; sense of accomplishment and excitement $[14,15]$. The first three values are related to a person's link with the rest of the society (external/apersonal value factor); the next two values represent an interpersonal value factor; and the remaining four values relate to an internal/personal value factor [1621]. 
During the past decades, several research studies have been launched to examine the connection between values and food purchase behavior from several aspects. The most important of them aim to reveal the connection between human values and the purchase of organic food products [20,22], while another study [23] surveyed the influence of food orientated values on consumer behavior.

However, switching to a healthy way of life or diet takes a long time since individuals go through several stages before they develop maintainable health behavior. The so-called Transtheoretical model of behavior change [24] assesses the individual's readiness to act on a new healthier behavior and provides strategies or processes of change to guide the individual through the stages of change to action and maintenance. The Transtheoretical model is also known by the abbreviation "TTM" and by the term "Stages of Change" [25,26].

The TTM is based on the premise that people are at different stages of motivational readiness for engaging in health behaviors and that intervention approaches are most useful when they are matched to a person's current stage of change [27]. The model describes how people modify a problem behavior or acquire a positive behavior. The Transtheoretical model has five stages [28]:
Precontemplation (not ready); Contemplation (getting ready); Preparation (ready); Action; Maintenance.

\subsection{Conceptual Framework}

In the course of a comprehensive analysis of special literature, no reference was found to research that examined the influence of personal (LOV) value-based segments on the change of health behavior (TTM) and on health-conscious food purchase behavior (HFPB) [29,30] although this context would provide important information for health protecting food manufacturers when developing a marketing strategy, even if application for specific product category requires further knowledge of the target market. Thus, the following objectives were established (Figure 1). In the first step, the original factor structure of the LOV items were tested on the Hungarian population and new factors were set which form reliable scales for further research. In the second step, the Hungarian population was segmented on the basis of LOV items [5]. In the third step, the objective was to find a significant correlation between the consumer groups based on LOV values, switching to a healthy diet (TTM) [24] and health-conscious food purchase behavior.

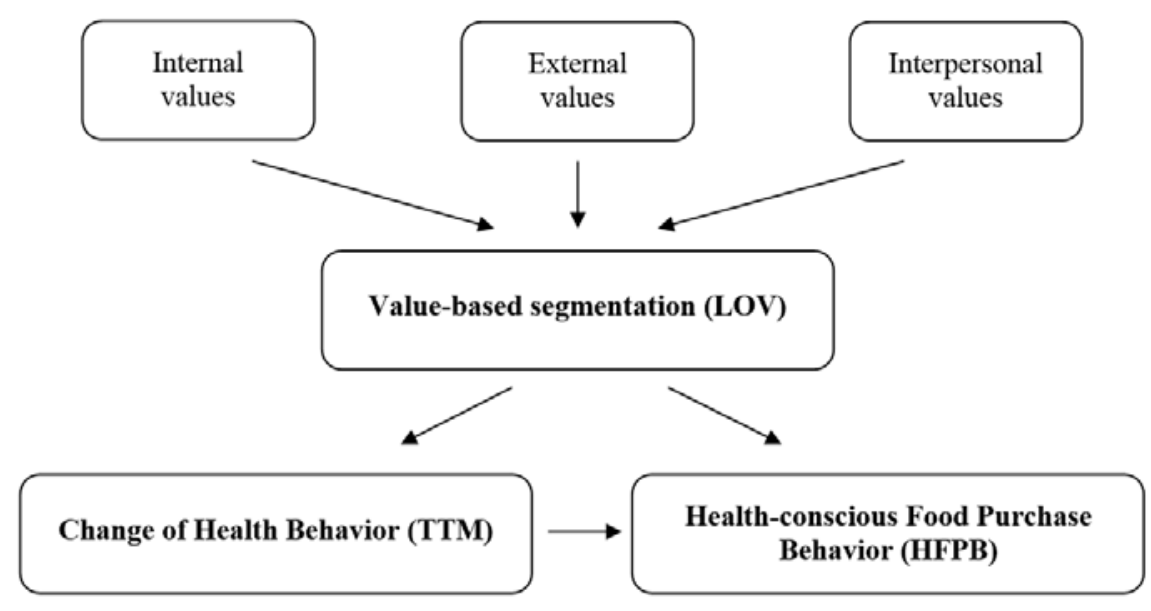

Figure 1. Conceptual framework of the research

\section{Materials and Methods}

\subsection{Sampling}

In order to achieve the set objective, a nationwide representative questionnaire-based survey was given to 1000 participants in Hungary, in 2013. In the case of 10 million inhabitants the sample size of 1000 ensures approximately 3\% sampling error. Representativeness for regions and types of settlement was ensured by the applied quoted sampling method. The sample pattern met the quotas previously defined by the Hungarian Central Statistical Office (HCSO). On the assigned settlements, a random walking method was used to ensure total randomness in selection. In the second step, the interviewed person within one household/family was selected by using the so-called birthday-key. The main point of the method is to select that consumer from the family members who has the appropriate age (18 or older) and whose date of birth (birthday) falls closest to the day of the interview. The legal age of majority was set as a criterion, because these consumers decide more independently on their consumption, and have higher purchasing power. With this method, randomness was ensured in the second step as well. Refusal was characteristic; the questions were answered in only $68 \%$ of the households, thus more households were needed to visit to reach the sample size of 1000 .

Since random walking does not ensure the sample is a reflection of the entirety of the population (the number of the female and elderly respondents was higher than the national average), the sample of the people was corrected using multi-dimensional weighing factors (gender and age) [31]. After these methods were applied, the sample was representative of the structure of the Hungarian population in all the four aspects (region, type of settlement, gender and age).

\subsection{Questionnaire}

In the first part of the questionnaire, the nine items of the LOV value scale were listed. The answers given to the 
nine items were indicated on a Likert scale with five grades given by the interviewers, where grade five meant "very important" and grade one meant "not important at all." The next question examined the process of switching to a healthier diet based on the Transtheoretical model. The applied stages were as follows on the questionnaire [28]. The third question of the questionnaire mentions seven statements referring to conscious food purchase (Food Purchase Behavior), which had to be answered on a five point Likert scale by the interviewees. On the scale grade five means "totally agree,” grade one means "totally disagree."

At the end of the questionnaire, the socio-demographic background variables were listed: the gender, age and education level of the respondents, the subjective income status (How do they feel about their income status compared to the average level?) and in which size community they live.

\subsection{Statistical Analysis}

In addition to the descriptive statistics, two- as well as multivariate analyses were made. The Bartlett test and the Kaiser-Meyer-Olkin measure were applied to prove the reasonableness of factor analysis (to find correlations between various variables). Combined factor and cluster analysis was used to define various consumer segments $[32,33,34,35]$. Because of the size of the sample, the nonhierarchic/K-means clustering method was used during our research. With the cluster analysis, the $\mathrm{F}$ values were taken into consideration, in order that those variables could be defined that are more suitable for forming more homogenous groups, as well as to define those variables with greater cluster forming power. The fulfillment of the one-way ANOVA requirements, specifically the normal distribution of the residuals and the homogeneity of variance, were tested by the Shapiro-Wilk's and the Levene's tests, respectively. In the cases where statistical significance differences were identified, the dependent variable were compared using Tukey's honestly significant difference (homoscedasticity) or Tamhane's T2 (heteroscedasticity) multiple comparison tests. Moreover, during the cross tabulation analysis, in order to identify the contribution of different cells to the significance of the chi-square, we used adjusted standardized residuals (ASR). The ASR followed the $t$ distribution. For ASR $>1.96$, $\mathrm{p}<0.05$ and for ASR $>2.56, \mathrm{p}<0.01$.

\section{Results}

\subsection{Value Order and Factor Structure}

In the first step of the research, the nine items of the value list (LOV) were tested on a five-grade interval scale, where 1 means "not important at all" and 5 means "very important”. The surveyed people were expected to say how important the values involved in the questionnaire are in their life (Table 1).

Table 1. Importance of LOV Values Among the Hungarian Population ( $N=1000)$

\begin{tabular}{|c|c|c|c|}
\hline \multirow{2}{*}{ Values } & \multicolumn{3}{|c|}{ Statistical indicators } \\
\cline { 2 - 4 } & Mean & Standard deviation & Coefficient of variation (\%) \\
\hline Sense of security & 4.65 & 0.627 & 13.48 \\
\hline Fun and enjoyment in life & 4.48 & 0.753 & 16.81 \\
\hline Sense of belonging & 4.39 & 0.858 & 19.54 \\
\hline Self-fulfillment & 4.29 & 0.845 & 21.36 \\
\hline Self-respect & 4.19 & 0.895 & 23.32 \\
\hline Warm relationships with others & 4.07 & 0.949 & 25.54 \\
\hline Sense of accomplishment & 4.01 & 1.024 & 25.46 \\
\hline Being respected & 3.99 & 1.016 & 45.61 \\
\hline Excitement & 2.89 & 1.318 & \\
\hline
\end{tabular}

First of all it, can be stated that for the Hungarian population, all the values are important except for one (excitement). The most important for them is security. The homogenous answers are referred to by the low standard deviation and coefficient of variation values. Next in line come fun and enjoyment in life, as well as the sense of belonging, the standard deviation and coefficient of variation are also low here. However, the next two values can be listed among the personal (internal) factors, selffulfillment and self-respect are outstandingly important to the majority of the Hungarians (with relatively low coefficient of variation). Warm relationship with others means the shaping and cultivation of sincere and deep friendships, which is followed by the sense of accomplishment and being respected by others. The least important value is looking for excitement; its importance comes well behind the other values.

Factor analysis was made in order to survey the structure of the values, as a result of which two factors could be separated (Table 2).

Table 2. Factors Formed Based on LOV Values (Rotated factor matrix)

\begin{tabular}{|c|c|c|c|}
\hline \multirow{2}{*}{ Factor names } & \multirow{2}{*}{ Values } & \multicolumn{2}{|c|}{ Value factors and factor loadings } \\
\hline & & Factor I. & Factor II. \\
\hline \multirow{6}{*}{ Self-actualizing values } & Sense of accomplishment & 0.739 & 0.330 \\
\hline & Being respected & 0.698 & 0.302 \\
\hline & Self-respect & 0.644 & 0.372 \\
\hline & Excitement & 0.580 & -0.330 \\
\hline & Self-fulfillment & 0.555 & 0.452 \\
\hline & Warm relationships with others & 0.545 & 0.385 \\
\hline \multirow{3}{*}{ Stability values } & Sense of security & 0.027 & 0.788 \\
\hline & Fun and enjoyment in life & 0.395 & 0.649 \\
\hline & Sense of belonging & 0.384 & 0.463 \\
\hline
\end{tabular}

Extraction Method: Maximum Likelihood; Rotation Method: Varimax; Rotation converged in 3 iterations; KMO = 0.890; Bartlett test $(\chi 2=3639.214$; p<0.001); Communalities: 0.338-0.655; Total Variance Explained: 51.568\%; N=1000. 
Self-fulfilling values make up the first factor (variance explained: 29.926\%).The reliability of the factor is reasonably high (Cronbach's alpha=0.833). Here, the majority of the factors can be ranged with the individual's personal features. Sense of accomplishment, being respected by others, self-respect and self-fulfillment stand out. A life full of excitement and warm relationships with others are also important. Self-actualizing values are complemented with an interpersonal value (warm relationships with others) and a Stability value (being respected). The second factor represents Stability values (and also one interpersonal value), where the explained variance is $21.642 \%$. The factor is considered to be reliable (Cronbach's alpha=0.692).Within the factor, the outstanding values are security, happiness and enjoyment in life and with smaller importance the sense of belonging.

\subsection{Value-based Clusters}

After the factor analysis, the value based segmentation of Hungarian consumers was carried out by cluster analysis. After the K-means clustering method, based on the tested factors, four value-based consumer segments could be separated. At first, the socio-demographic features of the clusters are described (Table 3), then the value-based consumer groups (clusters) are introduced (Table 4) according to the two-dimensional grouping of the factor analysis.

Table 3. Comparison of Socio-demographic Variables in Clusters, \% ( $\mathrm{N}=\mathbf{1 0 0 0})$

\begin{tabular}{|c|c|c|c|c|c|c|}
\hline \multirow{2}{*}{\multicolumn{2}{|c|}{ Variables }} & \multicolumn{4}{|c|}{ Comparison of socio-demographic variables, $\%$} & \multirow[b]{2}{*}{ Significance } \\
\hline & & $\begin{array}{l}\text { Moderately Value } \\
\text { Driven }\end{array}$ & $\begin{array}{l}\text { Security } \\
\text { Seekers }\end{array}$ & Disappointed & $\begin{array}{l}\text { Value } \\
\text { Oriented }\end{array}$ & \\
\hline \multicolumn{2}{|r|}{ Size of clusters } & 20.8 & 27.6 & 7.2 & 44.4 & - \\
\hline \multirow{2}{*}{ Gender } & Men & 53.4 & 39.5 & 52.8 & 49.1 & \multirow{2}{*}{0.011} \\
\hline & Women & 46.6 & 60.5 & 47.2 & 50.9 & \\
\hline \multirow{5}{*}{ Age group } & $18-29$ & 28.0 & 15.6 & 1.4 & 32.7 & \multirow{5}{*}{$<0.001$} \\
\hline & $30-39$ & 19.8 & 12.7 & 6.9 & 20.7 & \\
\hline & $40-49$ & 15.5 & 23.9 & 15.3 & 20.9 & \\
\hline & $50-59$ & 18.4 & 18.1 & 29.2 & 14.6 & \\
\hline & $>60$ & 18.4 & 29.7 & 47.2 & 11.0 & \\
\hline \multirow{4}{*}{ Education } & Elementary school & 17.8 & 16.7 & 31.9 & 9.7 & \multirow{4}{*}{$<0.001$} \\
\hline & Vocational school & 30.8 & 36.0 & 20.8 & 30.2 & \\
\hline & High school degree & 30.8 & 34.9 & 37.5 & 39.3 & \\
\hline & University degree & 20.7 & 12.4 & 9.7 & 20.8 & \\
\hline \multirow{6}{*}{$\begin{array}{l}\text { Subjective } \\
\text { income }\end{array}$} & Well below the average & 40.9 & 46.2 & 59.7 & 39.1 & \multirow{6}{*}{$<0.001$} \\
\hline & A bit below the average & 21.2 & 25.1 & 19.4 & 27.0 & \\
\hline & Average & 21.2 & 20.7 & 13.9 & 25.6 & \\
\hline & A bit above the average & 2.4 & 3.3 & 1.4 & 4.5 & \\
\hline & Well above the average & 1.9 & 0.7 & 4.2 & 0.9 & \\
\hline & No answer & 12.5 & 4.0 & 1.4 & 2.9 & \\
\hline \multirow{5}{*}{$\begin{array}{l}\text { Type of } \\
\text { settlement }\end{array}$} & Capital city & 19.3 & 17.7 & 15.5 & 19.9 & \multirow{5}{*}{$<0.001$} \\
\hline & County town & 15.9 & 24.5 & 16.9 & 24.2 & \\
\hline & Town with over 10,000 residents & 14.5 & 20.2 & 32.4 & 23.7 & \\
\hline & $\begin{array}{c}\text { Town with between } 2,000-10,000 \\
\text { residents }\end{array}$ & 31.4 & 17.3 & 14.1 & 19.4 & \\
\hline & $\begin{array}{l}\text { Settlement with less than 2,000 } \\
\text { residents }\end{array}$ & 18.8 & 20.2 & 21.1 & 12.9 & \\
\hline
\end{tabular}

Table 4. Consumer Segments (clusters) Formed Based on LOV Values and Their Features ( $N=1000)$

\begin{tabular}{|c|c|c|c|c|c|c|c|}
\hline \multirow[b]{2}{*}{ Values } & \multicolumn{3}{|c|}{ Features of the sample } & \multicolumn{4}{|c|}{ Features of the consumer segments } \\
\hline & F-value & Significance & $\begin{array}{c}\text { Sample- } \\
\text { mean }\end{array}$ & $\begin{array}{c}\text { Moderately Value } \\
\text { Driven }\end{array}$ & $\begin{array}{l}\text { Security } \\
\text { Seekers }\end{array}$ & Disappointed & $\begin{array}{c}\text { Value } \\
\text { Oriented }\end{array}$ \\
\hline \multicolumn{8}{|c|}{ Self-fulfilling values } \\
\hline Self-fulfillment & 219.657 & $<0.001$ & 4.29 & 3.84 & 4.12 & 3.05 & 4.82 \\
\hline Self-respect & 361.182 & $<0.001$ & 4.19 & 3.82 & 4.00 & 2.43 & 4.78 \\
\hline Sense of accomplishment & 487.398 & $<0.001$ & 4.01 & 3.65 & 3.54 & 2.08 & 4.78 \\
\hline $\begin{array}{c}\text { Warm relationships with } \\
\text { others }\end{array}$ & 179.626 & $<0.001$ & 4.07 & 3.66 & 3.96 & 2.58 & 4.58 \\
\hline Being respected & 378.153 & $<0.001$ & 3.99 & 3.67 & 3.53 & 2.19 & 4.72 \\
\hline Excitement & 134.468 & $<0.001$ & 2.89 & 3.11 & 2.11 & 1.45 & 3.51 \\
\hline \multicolumn{8}{|c|}{ Stability values } \\
\hline Sense of security & 659.153 & $<0.001$ & 4.65 & 3.67 & 4.97 & 4.56 & 4.92 \\
\hline Sense of belonging & 120.858 & $<0.001$ & 4.39 & 3.89 & 4.40 & 3.37 & 4.78 \\
\hline Fun and enjoyment in life & 275.068 & $<0.001$ & 4.48 & 3.80 & 4.60 & 3.42 & 4.89 \\
\hline
\end{tabular}

1-5 grade interval scale (1="not important at all”, 5=”very important"); Classify=K-means Cluster; Number of Clusters=4; Maximum Iteration=20; Missing Values $=$ Exclude Cases List-wise; One-Way ANOVA $\mathrm{p}<0.05$.

Next, the socio-demographic and value features of each group are introduced.

Moderately Value Driven: This segment makes up $20.8 \%$ of the sample (208 people). In this cluster, men are slightly overrepresented (53.4\%), with a lot of young men (18-29 years - 28.0\%; 30-39 years - 19.8\%), but compared to the average the rate of the age group of 40-49 is lower (15.5\%). The composition of this segment is wellbalanced according to education, $62.1 \%$ of the group live on income below the average. Relatively many of them live in the capital city (19.3\%), but the majority (31.4\%) lives in towns of between 2,000-10,000 people.

From the LOV values - compared to the average of the total sample - they only prefer alife full of excitement, which belongs to Self-actualizing values. With this result, they are ahead of two segments $(\mathrm{p}<0.05)$. However, compared to the Value Oriented group, they underestimate this value. Compared to the second and third clusters, they 
overestimate being respected by others, as well $(\mathrm{p}<0.05)$, while similarly to the second cluster, a sense of accomplishment is important to them ( $>>0.05)$. Compared to the other clusters, they significantly underestimate sense of security $(p<0.05)$, i.e. they make up the segment that takes most risks.

Security Seekers: This cluster is the second largest (276 people, 27.6\%). Women are strongly overrepresented (60.5\%), according to age the majority of the segment is between 40-49 years of age (23.9\%). The rate of skilled workers is the highest here (36.0\%), on the other hand the rate of people with university degrees is low (12.4\%). The rate of households living on lower than average income is higher than $70 \%$, and only a small rate of them live on higher salary (4.0\%). This property probably determines their attitude toward values. Relatively many of them live in county towns $(24.5 \%)$ or in villages with less than 2,000 people (20.2\%).

Compared to the total sample, but also compared to the segments of Moderately Value Driven and Disappointed security is more important to them $(\mathrm{p}<0.05)$, which is the most important property of the cluster. However, this value dimension is judged similarly by the Value Oriented ( $>0.05)$. Compared to the first and third clusters, they overestimate warm relationships with others, i.e. it is important to them to be accepted by their friends, family and the people around them $(\mathrm{p}<0.05)$. They like having a close and warm relationship with their friends, they look for a happy and meaningful life, and they feel safe if they have a lot of human relationships.

Disappointed: This cluster consists of only 72 consumers, representing $7.2 \%$ of the sample. Men slightly outnumber women in the segment (52.8\%), according to age group the rate of elderly people is significantly high (40-49 years, 15.3\%; 50-59 years, 29.2\%; older than 60 years, $47.2 \%)$. The rate of people younger than 39 is only $8.3 \%$. The rate of people with elementary school education is very high (31.9); however, the group is underrepresented regarding the rate of people with a university degree (9.7\%). From the four clusters, this group lives under the worst financial conditions (79.1\% of them live below average income). They typically come from towns with more than 10,000 people (32.4\%), or most of them live in towns with less than 2,000 people (21.1\%).

Compared to the total sample, they underestimate each value, they lag behind the other clusters in self-respect, sense of accomplishment, being respected, as well as excitement and warm relationships with others $(\mathrm{p}<0.05)$. One value is overrated in this group, this is a sense of security; however, its size is behind two other segments $(\mathrm{p}<0.05)$. The cluster is characterized by disappointment, reserve, loss of hope and the devaluation of values.

Value Oriented: This segment is the biggest of the four, with 444 people representing $44.4 \%$ of the sample. According to sex, the group is well balanced; according to age, people younger than 39 years of age are strongly overrepresented (18-29 years, 32.7\%; 30-39 years, 20.7\%). As a result, the rate of the people older than 60 is only $11.0 \%$, which represents the lowest value of all the segments. Within the cluster, people with a university degree are overrepresented (20.8\%) and the rate of people with high school education is the highest of the four groups here (39.3\%). Their higher social status also means a better financial situation: their job facilities are much better compared to the other clusters. Nearly $45 \%$ of them live in the capital city, or in county towns, and accordingly only few of them live in towns with less than 2,000 people (12.9\%).

Their devotion to values is higher than average, they take a leading position in every dimension. Compared to the other groups, they overestimate Self-actualizing (personal) values like self-fulfillment, self-respect and sense of accomplishment $(\mathrm{p}<0.05)$. Warm relationships with others, sense of belonging, being respected and sense of accomplishment are especially important to them. In these values, they perform better than the other segments $(p<0.05)$. The value judgment of the fourth cluster is just the opposite of that of the third group (Disappointed).

In order to be able to analyze the impact of values on health behavior, further surveys are necessary. It was suspected in advance that a higher rate of the Value Oriented state that they have started a healthier way of eating (change of health behavior) than people in the other segments. To support this hypothesis, a correlation was sought between switching to a healthier diet and the value clusters (Table 5).

Table 5. Switching to a Healthy Diet According to Value Clusters ( $\mathbf{N = 1 0 0 0})$

\begin{tabular}{|c|c|c|c|c|}
\hline \multirow{3}{*}{ Answer categories } & \multicolumn{4}{|c|}{ Division of answers among the clusters } \\
\hline & Moderately Value Driven & Security Seekers & Disap-pointed & Value Oriented \\
\hline & \multicolumn{4}{|c|}{$\%$} \\
\hline Pre-contemplation & 60.5 & 52.9 & 78.9 & 50.8 \\
\hline Contemplation & 20.5 & 21.5 & 15.5 & 23.1 \\
\hline Preparation & 9.0 & 10.9 & 1.4 & 7.6 \\
\hline Action & 6.5 & 6.7 & 1.4 & 7.6 \\
\hline Maintenance & 3.5 & 8.0 & 2.8 & 10.9 \\
\hline Total & 100.0 & 100.0 & 100.0 & 100.0 \\
\hline
\end{tabular}

$\chi 2=33.85, \mathrm{df}=12, \mathrm{p}<0.001$, Symmetric Measure $($ Cramer's V) $=0.107$.

From among the four segments the Value Oriented switched to a maintainable healthy diet way in the highest rate $(10.9 \%)$, and at the difference between the observed and the expected values is significant (ASR = 3.0). If the rate of those who have kept to a healthier diet for at least six months is added to this within the group (Action stage, $7.6 \%$ ), then $18.5 \%$ of the cluster can be considered conscious. Closest to them are the Security Seekers, for them security determines switching to a more conscious diet. However, only a small rate of the Moderately Value
Driven is considering a change in behavior, they prefer enjoyments. Almost $80 \%$ of the Disappointed do not prepare to switch to a diet considered healthier by them (Precontemplation stage) in the next six months (ASR = 4.1), while this value is the lowest (50.8\%) among the Value Oriented (ASR = -2.6).

\subsection{Health-conscious Food Purchase Behavior}


Additionally, seven food purchase behavior forms (FPB) were analyzed. From the point of view of the research, it was crucial to find out where health-conscious food purchase behavior (HFPB) lies among the seven forms of consumer behavior. The surveyed people were asked to answer statements on a five-grade Likert scale, where 1 means "do not agree at all”, and 5 means "totally agree”. The results are summarized in Table 6.

Table 6. Agreement with the Different Dimensions of Conscious Food Purchase Behavior Among the Hungarian Population (N=1000)

\begin{tabular}{|c|c|c|c|}
\hline \multirow{2}{*}{ Dimensions of food purchase behavior } & \multicolumn{3}{|c|}{ Statistical indicator } \\
\cline { 2 - 4 } & Mean & Standard deviation & Coefficient of variation (\%) \\
\hline Price consciousness & 4.35 & 0.862 & 19.82 \\
\hline Taste consciousness & 4.30 & 0.846 & 19.67 \\
\hline Needs of family & 4.25 & 0.954 & 22.45 \\
\hline Country-of-origin consciousness & 3.53 & 1.072 & 30.37 \\
\hline Health consciousness & 3.28 & 1.153 & 35.15 \\
\hline Quality consciousness & 3.20 & 1.104 & 37.69 \\
\hline
\end{tabular}

The consumers agree mostly that it is wisest to purchase food products at the best available prices. They are similarly conscious when they choose the best taste food products as well, the low standard deviation and coefficient of variation values refer to the homogeneity of the opinions. In addition to the taste and the price, the third most important view is the needs of the family; the homogeneity of the answers is equal with that of the first two points of views. The Hungarian consumers are far less conscious about the origin of the product, which does not favor the positioning of national foods. The conscious selection of health protective (functional) foods reached mediocre (3.28) qualification, so for the Hungarian people this factor is characteristically less important. The Hungarian consumers look for best quality products at higher prices more rarely and the low environmental conscious attitude may also be connected with this aspect.

Despite the fact that health-consciousness does not play a primary role in the consumers' decision making, we suspected that the health-conscious food purchase behaviors of the clusters based on the basis of the LOV values are significantly different from each other (Table 7).

Table 7. Connection Between the Value Clusters and Health-conscious Food Purchase Behavior $(\mathrm{N}=1000)$

\begin{tabular}{|c|c|c|c|}
\hline \multirow{2}{*}{ Value clusters } & \multicolumn{3}{|c|}{ Health-conscious food purchase behavior } \\
\cline { 2 - 4 } & Mean & Standard deviation & Coefficient of variation (\%) \\
\hline Disappointed & 2.25 & 1.082 & 48.09 \\
\hline Moderately Value Driven & 3.03 & 0.932 & 30.76 \\
\hline Security Seekers & 3.23 & 1.158 & 35.85 \\
\hline Value Oriented & 3.61 & 1.121 & 31.05 \\
\hline Total sample & 3.28 & 1.153 & 35.16 \\
\hline
\end{tabular}

${ }^{1}$ When choosing a food product I am conscious of purchasing a product with health protective effect.

1-5 stage interval scale (1=does not agree at all, 5=totally agree); One-Way ANOVA $p<0.001$.

According to the results, the cluster of the Value Oriented is the most devoted to health consciousness $(\mathrm{p}<0.05)$. They significantly differ from the Security Seekers, in the case of whom health-conscious diet may strengthen the sense of security and the Moderately Value Driven, who are bound to both value factors with moderate intensity. For the Disappointed groups, health consciousness is not important at all when they purchase food. Due to the lack of motivation, this factor is insignificant for them when shopping for food. In the case of the Disappointed, the high coefficient of variation (48.09\%) refers to a heterogeneous response structure. It can also be seen clearly that only the segment of the Value Oriented has a higher mean value (3.61) than that of the total sample (3.28), the mean value of the other three groups is lower. As a summary, it can be stated that value orientation is a determining factor in health conscious food purchasing behavior, because the arrangement of the consumer groups defined by the cluster analysis was consistent with the degree of the value orientation with significant differences.

\subsection{Connection between the Change of Health Behavior and Health-conscious Food Purchase Behavior}

Finally, a connection was sought between health behavior and health-conscious food purchase behavior (Table 8).

Table 8. Division of the Answers in Health-conscious Food Purchase Behavior and Switching to Health-conscious Diet (N=1000)

\begin{tabular}{|c|c|c|c|c|c|c|}
\hline \multirow{3}{*}{ Stages of change } & \multicolumn{6}{|c|}{ Affinity for health-conscious purchase behavior ${ }^{1}$} \\
\hline & $\begin{array}{c}\text { Does not } \\
\text { agree at all } \\
1\end{array}$ & 2 & 3 & 4 & $\begin{array}{c}\text { Totally } \\
\text { agree } \\
5\end{array}$ & Total \\
\hline & \multicolumn{6}{|c|}{ Division of answers, \% } \\
\hline Precontemplation & 75.0 & 81.3 & 57.8 & 44.4 & 36.4 & 55.3 \\
\hline Contemplation & 10.9 & 16.3 & 22.7 & 24.7 & 24.7 & 21.6 \\
\hline Preparation & 7.6 & 0.8 & 8.7 & 10.8 & 10.5 & 8.5 \\
\hline Action & 2.2 & 1.6 & 5.5 & 10.0 & 9.9 & 6.6 \\
\hline Maintenance & 4.3 & 0.0 & 5.3 & 10.1 & 18.5 & 8.0 \\
\hline Total & 100.0 & 100.0 & 100.0 & 100.0 & 100.0 & 100.0 \\
\hline
\end{tabular}

${ }^{1}$ When choosing a food product, I am conscious of purchasing a product with health protective effect. ASR $=-5.3-5.4, \mathrm{p}<0.001$.

The rate of the people in the Precontemplation stage, i.e. the rate of the disinterested, decreases significantly with the positive change of the health-conscious food purchase

behavior. A main part (75.0\%) of those who disregard the health protective effect of the products during shopping does not plan a change in their diet either $(\mathrm{ASR}=4.0$, 
$\mathrm{p}<0.01$ ). Contrary to them only $36.4 \%$ of those who totally agree with the statement rank themselves into this category (ASR $=-5.3, \mathrm{p}<0.01$ ). It can also be seen clearly that, parallel with the strengthening of health consciousness, the rate of those people who stress maintenance is increasing, $18.5 \%$ of those who totally agree with the statement do not return to their former eating habits (ASR $=5.4, \mathrm{p}<0.01$ ).

Table 9. Connection Between Health-conscious Food Purchase Behavior and Switching to Health-conscious Diet (N=1000)

\begin{tabular}{|c|c|c|c|}
\hline \multirow{2}{*}{ Stages of change } & \multicolumn{2}{|c|}{ Affinity for health-conscious purchase behavior ${ }^{1}$} \\
\cline { 2 - 4 } & Mean & Standard deviation & \\
\hline Precontemplation & 2.99 & 1.158 & 38.73 \\
\hline Contemplation & 3.49 & 1.049 & 30.06 \\
\hline Preparation & 3.56 & 1.093 & 30.70 \\
\hline Action & 3.80 & 0.953 & 25.08 \\
\hline Maintenance & 4.00 & 1.040 & 26.00 \\
\hline Total & 3.28 & 1.153 & 35.15 \\
\hline
\end{tabular}

${ }^{1}$ When choosing a food product, I am conscious of purchasing a product with health protective effect.

1-5 stage interval scale ( 1 = "does not agree at all", 5 = "totally agree"); One-Way ANOVA $\mathrm{p}<0.001$.

Based on the results of the analysis of variance, the consumer groups at different stages of switching to a health-conscious diet differ significantly from each other along the health conscious food purchasing behavior (Table 9). Consumers at the stage of precontemplation are the least interested towards health protective food products $(p<0.001)$. The consumers at the stages of contemplation and preparation are more interested, followed by the active consumer group with a higher average, but not significant, difference. The group in the phase of maintenance purchase health protective food products stands at a significantly higher rate than the consumer groups of contemplation and preparation. Thus, it is concluded that the transition process to a perceived healthier diet is related to health-conscious food purchasing behavior.

An easy way to comply with the journal paper formatting requirements is to use this document as a template and simply type your text into it.

The template is used to format your paper and style the text. All margins, column widths, line spaces, and text fonts are prescribed; please do not alter them. Your paper is one part of the entire proceedings, not an independent document. Please do not revise any of the current designations.

\section{Discussion}

In our research, we searched for connections between consumer values, switching to positive health behavior and health-conscious food purchase behavior. At first, the order of the importance of the LOV values was surveyed. Security came first among these values. The order of the $\mathrm{LOV}$ values is similar to the results of another Hungarian study [36] where the order of importance is the following: sense of security, sense of accomplishment, sense of belonging, self-respect, warm relationships with others, self-fulfillment, fun and enjoyment in life, being respected, excitement. Yet, there is a significant difference between other countries. In the research of Homer \& Kahle [16] or Chryssohoidis \& Krystallis [20], self-respect stands in first place. Kropp, Lavack, \& Silvera [21] also pointed out that there were interesting differences between countries. For example, while self-respect was rated the most important value for Norway, warm relationships with others was rated as the most important value in Korea.

Another significant difference is that, in the values of the Hungarian consumers, only two dimensions (factors) can be separated, those of self-actualization and stability;

the interpersonal values are embedded into the two main factors. The stability integrates the values of security, happy life and sense of belonging which are considered to be more fundamental than the values of self-fulfillment, self-esteem, success, social recognition, excitement, fun and enjoyable life that form the self-actualization factor. Among the motivation theories, a similar structure can be observed in Maslow's [13] hierarchy of needs. However, due to its two-factor structure, the structure fits better into Herzbergs' model [37]. Security or hygienic requirements, in the Herzberg sense, appear in both theories as elementary needs, which is consistent with the pattern of the segmentation, because within the clusters, there can be found a pattern where the stability factor is outstanding. While self-actualization is low, the reverse pattern cannot be discovered. It therefore appears that the values of selfactualization will not appear as long as stability is not guaranteed. The social motivations in both theories are situated between the safety or hygienic and selfactualization needs. According to our survey the interpersonal values cannot be resolved in a separate factor, presumably social relations can be classified into one of the two factors according to their functions. Thus, interpersonal values can enhance the sense of security, as the sense of belonging gives the impression of social support. However, the same category can serve selfactualization needs as well, in so far as these values strengthen the individuals' position (for example social recognition). In special literature, as has been outlined before, the Kahle values form three well-separated factors [16-21] however, it could not be verified in the Hungarian sample. Based on the comparison of our results and the related literature, the application of the LOV scale can result in a different factor structure according to region and country. That is why it is necessary to survey each country and culture independently.

Kamakura \& Novak [2], as well as Chryssohoidis \& Krystallis [20], carried out avalue based consumer segmentation. Similar to our results, they ranked the surveyed people into four clusters according to the Kahle value list's three dimensional grouping [16]. However, in their researches based on socio-demographic properties, they found significant correlations only in the case of a few factors, or not at all, so in this respect - as far as we know - our results are unique. A similar novelty is the comparison of the value based segments and the change of health behavior, which does not make a comparison with previous research possible.

In the case of the Hungarian population, an interesting connection can be observed if the value factors of stability 
(collectivism) and self-actualization (individualism) are placed in historical context. Before the change of regime in 1989, the socialist society emphasized the well-being of the society as a whole, and the sense of security amongst other collectivist values were prioritized. In the years following 1989, in line with the transition to a Western European market economy, the individualistic values of personal happiness, self-fulfillment and career development have evolved in Hungary again. While the impacts of social and economic uncertainty impact culture, politics and markets, as Wiwczaroski [40] has discussed, the impacts of sudden, rapid and constant change seen since 1989 have led to a sociopolitical environment where populations, especially in former Eastern Bloc countries, decry a loss of control over their own fates, as well as a perceived threat to a nation's sense of identity (2004). Longitudinal value studies have shown [19] that this value shift, until the time of the 2005 study, had not occurred in Hungary, and although individualistic values appeared even among young people, the need for safety was reasonably high and a low willingness to assume risks was found. A possible explanation is [39] the social and economic uncertainty caused by the regime change itself, and according to Schwartz and Bardis' prediction in 1997, the need for safety decreases and the individualistic values increase parallel with the stabilization of the new system. The expected change in the study of Hofmeister-Tóth and Simányi in 2005 can hardly be seen to emerge, but by the time of the data collection of the present study (2013), a stronger shift could have been occurred towards individualistic values. However, the global economic crisis beginning in 2008 affected Hungary severely, leading to high level of repeated periods of uncertainty. Therefore, a sense of security has become the most important value in the Hungarian population in 2013. It is an interesting question how these values will develop in the next decade. Although this segmentation describes the main value dimensions of consumers, further research is needed to refine the results possibly by defining subsegments of the four main segments or by involving other variables.

\section{Conclusions}

According to our results, in the value order of the Hungarian population, the stability and the selfactualization values dominate; for the majority, the satisfaction of security and social or basic needs is the biggest challenge. However, internal values such as selffulfillment, self-respect and a sense of accomplishment are the second most important. New research needs to be done to discover whether the situation is similar in other Eastern European countries (common social and cultural background) or whether we would obtain differing value structures for each country from that of Hungary.

Based on the surveyed factors, four value based consumer segments could be separated: these are the Moderately Value Driven, the Security Seekers, the Disappointed and the Value Oriented groups. From them, the cluster of the Value Oriented group forms the primary target group for health-protective food products. Their commitment to values is above the average, they take a leading position in all the dimensions. This cluster basically involves younger, open, optimistic people with future prospects, whose social position is higher than average. From the four segments, the cluster of the Value Oriented consumers switched to a perceived healthier diet at the biggest rate. Closest to them are the Security Seekers, whose need for security also manifest in conscious food consumption this shows us, that the rate of value orientation is defining for activity regardless of its content. The content actually only contributes to form the substance of the marketing message for the various target groups. In spite of this, generally, it can be stated that the rate of activities connected to health behavior is low in Hungary, independently from any group, and it is far behind the level of importance of the values. This result is shown by how, even in the segment of the Value Oriented consumers, the rate of those who reached the level of maintenance is only $11 \%$.

Based on the results of the research, the following summary can be made: Based on the Kahle value list, a new factor structure was found that applies to the Hungarian population that can be used as new scales in future research. This analysis served as a basis for a value based consumer segmentation of the Hungarian population and the examination of these segments resulted in a finding that value orientation is connected with behavioral change and health-conscious food purchasing behavior. As a result, in this field, great facilities lay both in entrepreneurial and collective marketing communications. The results of the research can be used by those (functional) food producers who determine their target groups and make their marketing programs based on social values.

In summary, it can be stated that, according to the findings of the research, there is a significant connection between personal values, change of health behavior and health-conscious food purchase behavior.

\section{Acknowledgement}

The support of the New Hungary Development Plan (TÁMOP 4.2.2/B-10/1) is gratefully acknowledged.

\section{References}

[1] Valette-Florence, P., "Specificites et apports des valeurs au champ d'investigation marketing," Publications de Recherche du CERAG, no. 88-24, Ecole Superieure des Affaires, Universite des Sciences Socials de Grenoble, 1988.

[2] Kamakura, W. A. and Novak, T. P., "Value-system segmentation. Exploring the meaning of LOV," Journal of Consumer Research, 19, 119-132, 1992.

[3] Rokeach, M., The nature of human values, Free Press, New York, 1973.

[4] Mitchell, A., The nine American life styles, New York: Warner, New York, 1983.

[5] Kahle, L. R., Social values and social change: adaptation to life in America, Praeger, New York, 1983.

[6] Schwartz, S. H., "Universals in the content and structure of values: theoretical advances and empirical tests in 20 countries," in Advances in Experimental Social Psychology, Academic Press, New York, 1992, 1-65.

[7] Beatty, S. E., Kahle, L. R. and Homer, P., "Personal values and gift-giving behaviors: A study across culture," Journal of Business Research, 22, 149-157, 1991. 
[8] Goldsmith, R. E., Freiden, J. B. and Kilsheimer, J. C., "Social values and female fashion leadership: a cross-cultural study," Psychology and Marketing, 10, 399-411, 1993.

[9] Kahle, L. R., Beatty, S. E. and Homer, P., "Alternative measurement approaches to consumer values: The List of Values (LOV) and Values and Life Style (VALS)," Journal of Consumer Research, 13 (3), 405-409, 1986.

[10] Kahle, L. R. and Kennedy, P., "Using the List of Values (LOV) to understand consumers," Journal of Services Marketing, 2 (4), 4956, 1988.

[11] Beatty, S. E., Kahle, L. R., Homer, P. and Misra, S., "Alternative measurement approaches to consumer values: the LOV and the Rokeach Value Survey," Psychology and Marketing, 2, 181-200, 1985.

[12] Feather, N. T., "Protestant ethic, conservatism and values," Journal of Personality and Social Psychology, 46 (5), 1132-1141, 1984.

[13] Maslow, A. H., Motivation and personality, New York: Harper and Row, New York, 1954, 80-106.

[14] Humayun, K. and Hasnu, S., "An analysis of consumer values, needs and behavior for liquid milk in Hazara, Pakistan," in Proceedings of 2nd CBRC, Lahore, Pakistan, 1-15, 2009.

[15] Kopanidis, F., "Towards the development of a Personal Values Importance Scale (PVIS)," in Proceedings of the 2009 ANZMAC Australian \& New Zealand Marketing Academy(ANZMAC) Conference, Melbourne, Australia, 1-9, 2009.

[16] Homer, P. and Kahle, L. R., "A structural equation test of the Value-Attitude-Behavior Hierarchy," Journal of Personality and Social Psychology, 54 (4), 638-646, 1988.

[17] Shim, S. and Eastlick, M. A., "The hierarchical influence of personal values on mall shopping attitude and behavior," Journal of Retailing, 74 (1), 139-160, 1998.

[18] Kim, J. O., Forsythe, S., Gu, Q. and Moon, S. J., "Cross-cultural consumer values, needs and purchase behavior," Journal of Consumer Marketing, 19 (6), 481-502, 2002.

[19] Jajawardhena, C., "Personal value's influence on e-shopping attitude and behavior," Internet Research, 14 (2), 127-138, 2004.

[20] Chryssohoidis, G. M. and Krystallis, A., "Organic consumers' personal values research: Testing and validating the list of values (LOV) scale and implementing a value-based segmentation task," Food and Quality Preferences, 16 (7), 585-599, 2005.

[21] Kropp, F., Lavack, A. M. and Silvera, D. H., "Values and collective self-esteem as predictors of consumer susceptibility to interpersonal influence among university students," International Marketing Review, 22 (1), 7-33, 2005.

[22] Baker, S., Thompson, K., Engelken, J. and Huntley, K., "Mapping the values driving organic food choice," European Journal of Marketing, 38 (8), 995-1012, 2004.

[23] Hauser, M., Nussbeck, F. W. and Jonas, K., "The impact of foodrelated values on food purchase behavior and the mediating role of attitudes: a Swiss study," Psychology \& Marketing, 30 (9), 765778, 2013.

[24] Prochaska, J. O. and DiClemente, C. C., The transtheoretical approach: crossing traditional boundaries of change, Dorsey Press, Homewood III., 1984.

[25] Greene, G. W., Rossi, S. R., Rossi, J. S., Velicer, W. F., Fava, J. L. and Prochaska, J. O., "Dietary applications of the Stages of Change Model," Journal of the American Dietetic Association, 99 (6), 673-678, 1999.

[26] Prochaska, J. O., Butterworth, S., Redding, C. A., Burden, V., Perrin, N., Leo, M., Flaherty-Robb, M. and Prochaska, J. M., "Initial efficacy of MI, TTM tailoring and HRI's with multiple behaviors for employee health promotion," Preventive Medicine, 46 (3), 226-231, 2008.

[27] Ruggiero, L., "Helping people with diabetes change behavior: from theory to practice," Diabetes Spectrum, 13 (3), 125, 2000.

[28] Prochaska, J. O., Norcross, J. C. and DiClemente, C. C., Changing for good: the revolutionary program that explains the six stages of change and teaches you how to free yourself from bad habits, W. Morrow, New York, 1994

[29] Siró, I., Kápolna, E., Kápolna, B. and Lugasi, A., "Functional food. Product development, marketing and consumer acceptance. A review," Appetite, 51, 456-467, 2008.

[30] Szakály, Z., Szente, V., Kövér, Gy., Polereczki, Zs. and Szigeti, O. "The influence of lifestyle on health behavior and preference of functional foods," Appetite, 58, 406-413, 2012.

[31] Grafen, A. and Hails, R., Modern statistics for the life sciences, Oxford University Press, USA, 2002, 1-368.

[32] Blankenship, A.B. and Breen, G.E., State of the art marketing research, American Marketing Association, NTC Business Books, USA, Illinois, 1993, 1-580.

[33] Clifton, P., Nguyen, H. and Nutt, S., Market research: using forecasting on business, Oxford: Butterworth-Heinemann, Oxford, 1992, 1-266.

[34] Malhotra, N.K., Marketing Research, Academic Publisher, Hungary, 2008.

[35] Scipione, P. A., Practice of market research, Budapest: Springer Hungarica Publisher, Budapest, 1994.

[36] Piskóti, I., "The model of social marketing and its operation in Hungary," Publications of Economics, 6 (1), 103-120, 2012.

[37] Herzberg, F., Mausnek, B. and Snydebman, B., The Motivation to Work(Second Edition). New York: John Wiley and Sons, New York, 1959.

[38] Hofmeister-Tóth, Á. and Simányi, L. "Cultural Values in Transition," Society and Economy, 28 (1), 41-59, 2006.

[39] Schwartz, S. H. and Bardi, A., "Influences of Adaptation to Communist Ruleon Value Prioritiesin Eastern Europe," Political Psychology, 18 (2), 385-410, 1997.

[40] Wiwczaroski, T.B., "Globalization and the new intolerance. Approaches to discussing political terminology in cultural classes," Győri nyelvi mozaik, 2, 188-197, 2004. 